\title{
Association of endoscopic and histological remission with clinical course in patients of ulcerative colitis
}

\author{
Vikram Narang ${ }^{1}$, Ravneet $\operatorname{Kaur}^{1}$, Bhavna Garg ${ }^{1}$, Ramit Mahajan ${ }^{2}$, Vandana Midha ${ }^{3}$, Neena Sood ${ }^{1}$, \\ Ajit Sood ${ }^{2}$ \\ Departments of ${ }^{1}$ Pathology, ${ }^{2}$ Gastroentrology, and ${ }^{3}$ Internal Medicine, Dayanand Medical College and Hospital, Ludhiana, India
}

Background/Aims: The therapeutic goal for treating ulcerative colitis (UC) patients has shifted to achieving mucosal healing over the past few years. However, at present, limited data is available on the correlation between endoscopic findings and histological remission in patients with endoscopic mucosal healing. Methods: This was a prospective observational study conducted over a period of 18 months (January 2014 to June 2015) at Dayanand Medical College and Hospital, Ludhiana, Punjab, India. Patients diagnosed with UC who had been in clinical remission $(n=76)$ for at least 6 months were evaluated for endoscopic remission. Those in endoscopic remission (Mayo score $\leq 1 ; 46 / 76,60.5 \%$ ) were subjected to multiple biopsies from the rectosigmoid region and histological remission, which was then defined as grade $0 / 1$ as per the Geboes criteria. Results: Of the 46 patients in endoscopic remission (age, 18-73 years; male:female=1.5:1.0), majority had E1 (proctitis) disease (21/46, 45.6\%) followed by E2 (left sided colitis) (18/46, 39.1\%) and E3 disease (pancolitis) $(7 / 46,15.2 \%)$ at baseline. Histological remission was noted in $67.3 \%$ (31/46) of the patients, while $32.7 \%$ (15/46) still retained the histologically active disease in the form of infiltration of the lamina propria by eosinophils and neutrophils (13/15, 86.6\%), cryptitis (14/15, 93.3\%), and crypt abscesses (8/15, $53.3 \%)$. On follow-up, after 1 year, $87.1 \%$ (27/31) of the patients who had been in histological remission remained clinically asymptomatic, while $12.9 \%$ (4/31) had relapsed. Among the 15 histologically active patients, $46.6 \%(7 / 15)$ remained in clinical remission, while 53.3\% (8/15) had relapsed. Conclusions: Histological remission, rather than endoscopic remission, predicts a sustained clinical remission and allows monitoring of therapy for the subsequent disease course in patients with UC. (Intest Res 2018;16:55-61)

Key Words: Mucosal healing; Histological remission; Colitis, ulcerative

\section{INTRODUCTION}

Ulcerative colitis (UC) is a chronic IBD with a relapsing and remitting course. The optimal goal of treatment of IBD is the complete resolution of the inflammatory process, and this is achieved only when patients in clinical remission have a corresponding mucosal healing. Mucosal healing may be observed on both endoscopic and histological aspects, and at present a standardized definition of mucosal healing for

Received April 12, 2017. Revised June 10, 2017. Accepted June 16, 2017. Published online September 4, 2017

Correspondence to Vikram Narang, Department of Pathology, Dayanand Medical College and Hospital, Tagore Nagar, Civil Lines, Ludhiana 141001, India. Tel: +91-1614687619, E-mail: drvikramnarang@yahoo.com
IBD patients does not exist. Although most studies on mucosal healing focus on endoscopic scores, some experts have suggested histological inflammation is a better predictor of future clinical relapse than endoscopic appearance alone. ${ }^{1,2}$ The present analysis was planned to evaluate the association between clinical remission, endoscopic remission, and histopathological parameters. Current practice in UC patients is to achieve endoscopic mucosal healing and no guidelines mention histological remission. To the best of our knowledge, this is the first study from Asia highlighting the discrepancy between endoscopic and histologic remission.

\footnotetext{
(c) Copyright 2018. Korean Association for the Study of Intestinal Diseases. All rights reserved.

This is an Open Access article distributed under the terms of the Creative Commons Attribution Non-Commercial License (http://creativecommons.org/licenses/by-nc/4.0)

which permits unrestricted non-commercial use, distribution, and reproduction in any medium, provided the original work is properly cited.
} 


\section{METHODS}

\section{Setting}

This was a prospective, observational study assessing the association between the histological remission and longterm clinical course in patients with UC, conducted in the Departments of Gastroenterology and Pathology, Dayanand Medical College and Hospital, Ludhiana, between January 2014 to June 2015 (18 months) and subsequently followed up for 1 year.

\section{Patients and Treatment}

The diagnosis of UC was based on accepted clinical, endoscopic, and histological criteria. Clinical remission was defined as a Simple Clinical Colitis Activity Index $\leq 2$ for at least 6 months and endoscopic remission (normal with clearly visible vascular pattern or erythema with decreased vascular pattern but no bleeding, i.e., Mayo score $\leq 1$ ). Patients with active disease on endoscopy (Mayo $\geq 2$ ) were excluded.

\section{Histological Evaluation}

Patients who were in clinical remission $(\mathrm{n}=76)$ for at least 6 months were subjected to ileocolonoscopy. Patients who were in endoscopic remission $(46 / 76,60.5 \%)$ were subjected to 4 biopsies from the rectosigmoid region to evaluate histological activity. As per Geboes criteria (2000), grade 0/1 was defined as histological remission. ${ }^{3}$ All the biopsies were evaluated by 1 gastrointestinal pathologist (N.S.). The patient characteristics (age, gender, endoscopic findings, duration of disease, duration of remission, and histopathology) were recorded (Fig. 1). Written consent was obtained from the patients and ethical approval from the Institutional Review Board of Dayanand Medical College and Hospital (ECR/715/ Inst/PB/2015) was also obtained in April/May 2013.
Table 1. Baseline Characteristics of the Patients

\begin{tabular}{|c|c|}
\hline Characteristic & Value $(n=46)$ \\
\hline \multicolumn{2}{|l|}{ Age (yr) } \\
\hline$<30$ & $10(21.7)$ \\
\hline$\geq 30$ & $36(78.3)$ \\
\hline \multicolumn{2}{|l|}{ Sex } \\
\hline Male & 27 (58.7) \\
\hline Female & $19(41.3)$ \\
\hline \multicolumn{2}{|l|}{ Hemoglobin (g/dL) } \\
\hline$<10$ & $16(34.8)$ \\
\hline$\geq 10$ & $30(65.2)$ \\
\hline \multicolumn{2}{|l|}{$\mathrm{CRP}(\mathrm{mg} / \mathrm{L})$} \\
\hline$<6$ & $31(67.3)$ \\
\hline$\geq 6$ & $15(32.7)$ \\
\hline \multicolumn{2}{|l|}{$\mathrm{ESR}(\mathrm{mm} / \mathrm{h})$} \\
\hline $5-20$ & $12(26.1)$ \\
\hline $21-60$ & $18(39.1)$ \\
\hline $61-90$ & $16(34.8)$ \\
\hline \multicolumn{2}{|l|}{ Duration of disease (yr) } \\
\hline$<5$ & $27(58.7)$ \\
\hline $5-9$ & $8(17.4)$ \\
\hline$\geq 10$ & $11(23.9)$ \\
\hline \multicolumn{2}{|c|}{ Extent of disease at the time of diagnosis } \\
\hline E1 (proctitis) & $21(45.6)$ \\
\hline E2 (left-sided colitis) & $18(39.1)$ \\
\hline E3 (extensive colitis) & 7 (15.2) \\
\hline \multicolumn{2}{|l|}{ Duration of clinical remission } \\
\hline $6 \mathrm{mo}-2 \mathrm{yr}$ & $38(82.6)$ \\
\hline$>2 \mathrm{yr}_{1}<5 \mathrm{yr}$ & $6(13.0)$ \\
\hline$\geq 5 \mathrm{yr}$ & $2(4.3)$ \\
\hline \multicolumn{2}{|l|}{ Extraintestinal manifestations } \\
\hline Present & 5 (10.9) \\
\hline Absent & $41(89.1)$ \\
\hline
\end{tabular}

Values are presented as number (\%).

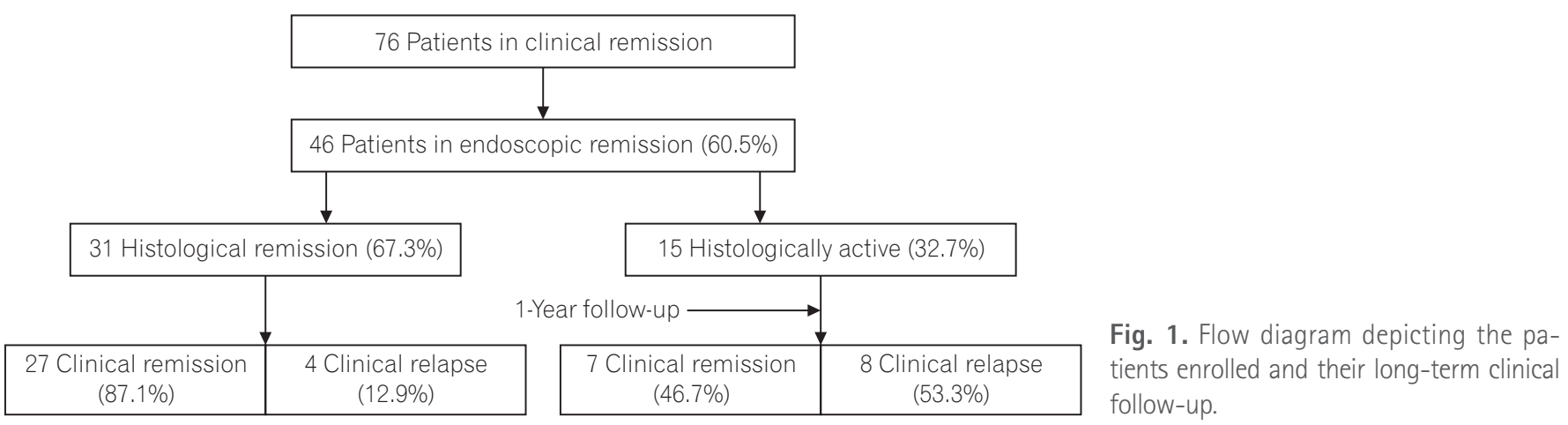



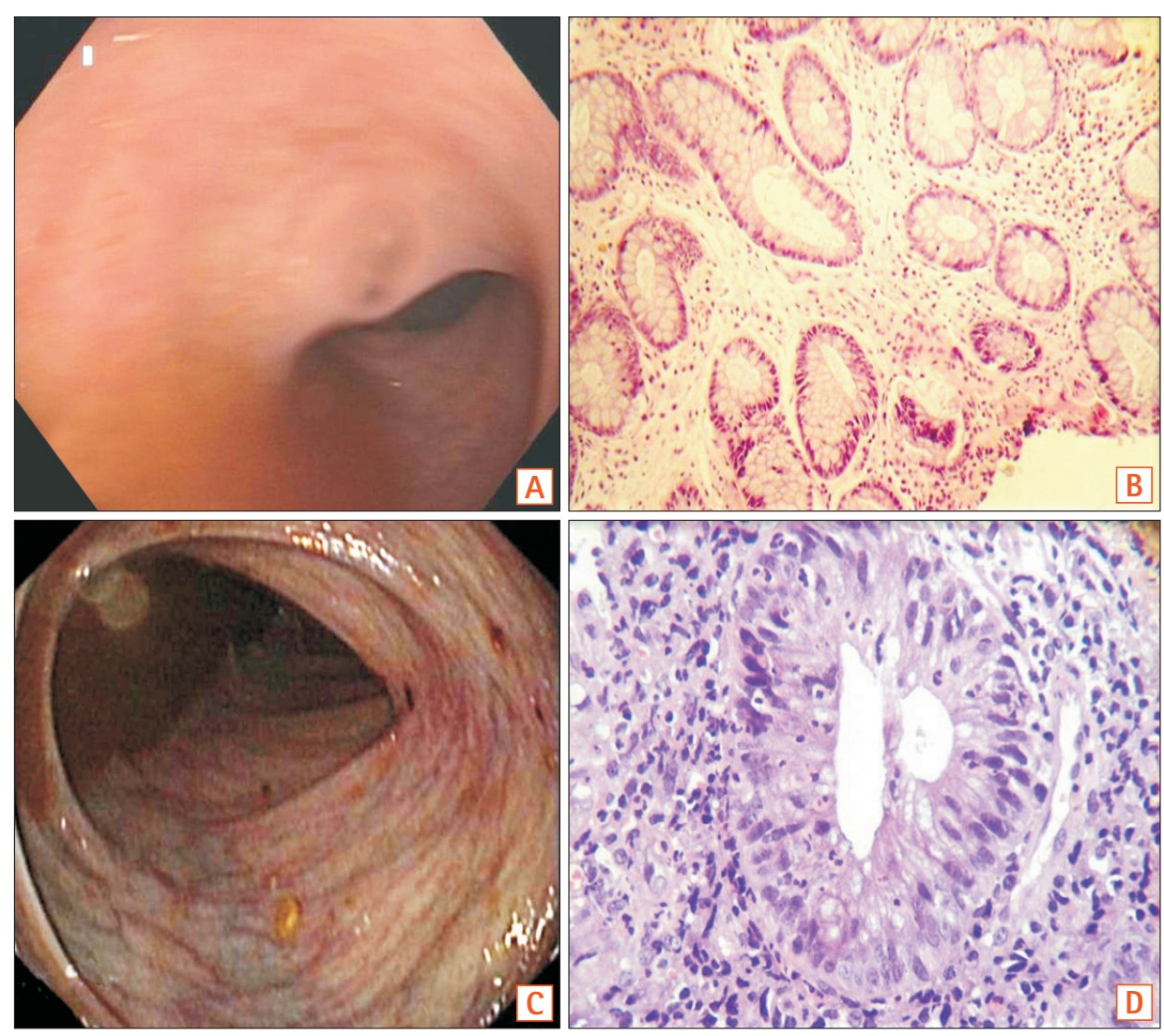

Fig. 2. (A) Endoscopy Mayo score 0; (B) histopathological examination of the same patient exhibiting mild crypt distortion only (Geboes grade, 0.1) $(\mathrm{HCtE}, \times 200)$. (C) Endoscopy Mayo score 1; (D) histopathological examination of the same patient showing significant acute inflammatory infiltrates in the lamina propria along with evidence of cryptitis (Geboes grade, 3.1) $(\mathrm{HEE}, \times 400)$.

\section{Follow-up}

The patients showing endoscopic remission were maintained on a stable dose of mesalamine and azathioprine/6mercaptoprine and were followed up for 1 year to observe the clinical course. Patients on steroids, biological therapies, rectal mesalamine, or steroid enemas were not included in the present study.

\section{Statistical Analysis}

The data collected were subjected to statistical analysis. Mean and standard deviation were computed and paired $t$ and Z-tests were applied to evaluate the association between the 2 variables and to compare the means of the 2 groups. A significance difference was defined at an appropriate degree of freedom at the $1 \%$ and $5 \%$ levels of significance $(P<0.05)$.

\section{RESULTS}

\section{Baseline Characteristics}

Seventy-six patients had a sustained clinical remission during 2014 to 2015, the duration of which ranged from 6 months to $>5$ years. Of these 76 patients, 46 were in endoscopic remission (age, 18-73 years; male:female=1.5:1.0). Prior to starting treatment, these patients had E1 disease (proctitis) in 45.6\% (21/46) followed by E2 (left sided colitis; 18/46, 39.1\%) and E3 (extensive colitis; 7/46, 15.2\%) disease. According to the average duration of remission at the time of analysis, the patients were grouped as follows: 6 months to $<2$ years $(38 / 46,82.6 \%), 2$ to 5 years $(6 / 46,13.0 \%)$, and $>5$ years $(2 / 46,4.3 \%)$ (Table 1$)$.

\section{Histopathological Parameters}

The patients in endoscopic remission were subjected to endoscopic biopsies from the rectosigmoid region. Histological remission was noted in $67.3 \%$ of patients $(31 / 46)$, while $15(32.7 \%)$ patients still had histologically active disease in the form of infiltration of the lamina propria by eosinophils and neutrophils $(13 / 15,86.6 \%)$, cryptitis $(14 / 15,93.3 \%)$, and crypt abscesses (8/15, 53.3\%) (Fig. 2). The histological grades of these patients are summarized in Table 2. Of the 31 patients in histological remission, 16 (51.6\%) had mild structural changes while 14 (41.9\%) had no structural changes ac- 
Table 2. Histological Parameters as per Geboes Criteria

\begin{tabular}{|c|c|c|c|}
\hline Histological parameter & Histological remission $(n=31)$ & Histologically active $(n=15)$ & $P$-value \\
\hline Grade 0 (structural changes) & & & 0.016 \\
\hline 0.0 (no abnormality) & 14 & 1 & \\
\hline 0.1 (mild abnormality) & 16 & 11 & \\
\hline 0.2 (mild or moderate diffuse or multifocal abnormality) & 1 & 3 & \\
\hline 0.3 (severe diffuse or multifocal abnormalities) & 0 & 1 & \\
\hline Grade 1 (chronic inflammatory infiltrate) & & & 0.006 \\
\hline 1.0 (no increase) & 0 & 0 & \\
\hline 1.1 (mild but unequivocal increase) & 21 & 3 & \\
\hline 1.2 (moderate increase) & 10 & 11 & \\
\hline 1.3 (marked increase) & 0 & 1 & \\
\hline Grade 2A (presence of eosinophils in the lamina propria) & & & 0.001 \\
\hline 2A.0 (no increase) & 31 & 2 & \\
\hline 2A.1 (mild but unequivocal increase) & 0 & 10 & \\
\hline 2A.2 (moderate increase) & 0 & 2 & \\
\hline 2A.3 (marked increase) & 0 & 1 & \\
\hline Grade 2B (presence of neutrophils in the lamina propria) & & & 0.001 \\
\hline 2B.0 (no increase) & 31 & 1 & \\
\hline 2B.1 (mild but unequivocal increase) & 0 & 8 & \\
\hline 2B.2 (moderate increase) & 0 & 6 & \\
\hline 2B.3 (marked increase) & 0 & 0 & \\
\hline Grade 3 (neutrophils in epithelium) & & & 0.001 \\
\hline 3.0 (none) & 31 & 4 & \\
\hline 3.1 (<5\% crypts involved) & 0 & 10 & \\
\hline 3.2 (<50\% crypts involved) & 0 & 1 & \\
\hline 3.3 (>50\% crypts involved) & 0 & 0 & \\
\hline Grade 4 (crypt destruction) & & & 0.001 \\
\hline 4.0 (none) & 31 & 7 & \\
\hline 4.1 (probable local excess) & 0 & 8 & \\
\hline 4.2 (probable marked attenuation) & 0 & 0 & \\
\hline 4.3 (unequivocal crypt destruction) & 0 & 0 & \\
\hline Basal plasmacytosis & & & 1.000 \\
\hline Present & 2 & 1 & \\
\hline Absent & 29 & 14 & \\
\hline
\end{tabular}

cording to the Geboes criteria, and 21 (67.7\%) of the patients in histological remission had mild chronic inflammatory cells in the lamina propria while $11 / 15$ patients $(73.3 \%)$ in the histologically active category had moderate increases and $13.3 \%$ had marked increases in chronic inflammatory infiltrates into the lamina propria (Table 2). Histological remission did not depend on the duration $(P=0.807)$ or extent
$(P=0.360)$ of the disease but the Mayo score $(0 / 1)$ was significant in predicting remission $(P=0.047)$ (Table 3$)$. There was no clinical significance for the presence of basal lymphoid aggregates or basal plasmacytosis $(P=1.000)$ (Table 2). 
Table 3. Factors Predicting Histological Remission

\begin{tabular}{|c|c|c|c|}
\hline Factor & $\begin{array}{c}\text { Histological } \\
\text { remission }\end{array}$ & $\begin{array}{l}\text { Histologically } \\
\text { active }\end{array}$ & $P$-value \\
\hline Age (yr) & & & 0.842 \\
\hline$<30$ & 7 & 3 & \\
\hline$\geq 30$ & 24 & 12 & \\
\hline Sex & & & 0.073 \\
\hline Male & 21 & 6 & \\
\hline Female & 10 & 9 & \\
\hline Duration of disease (yr) & & & 0.807 \\
\hline$<5$ & 21 & 9 & \\
\hline $5-9$ & 4 & 3 & \\
\hline$\geq 10$ & 6 & 3 & \\
\hline \multicolumn{2}{|c|}{ Duration of clinical remission } & & 0.602 \\
\hline $6 \mathrm{mo}-2 \mathrm{yr}$ & 25 & 13 & \\
\hline$>2,<5 \mathrm{yr}$ & 4 & 2 & \\
\hline$\geq 5 \mathrm{yr}$ & 2 & 0 & \\
\hline \multicolumn{2}{|c|}{ Extent of disease at diagnosis } & & 0.360 \\
\hline E1 & 19 & 6 & \\
\hline E2 & 9 & 6 & \\
\hline E2 & 3 & 3 & \\
\hline Mayo score & & & 0.047 \\
\hline MES 0 & 27 & 9 & \\
\hline MES 1 & 4 & 6 & \\
\hline
\end{tabular}

MES, mayo endoscpoic subscore.

\section{Follow-up}

When followed up for 1 year, nearly twice the number of patients in histological remission remained in clinical remission when compared with those with histological activity ( $87.1 \%$ vs. $46.6 \%$, respectively, $P=0.006$ ). As seen in Table 4 , relapses defined by the histological score $(P=0.001)$ did not depend on patient factors like age or sex, or duration of clinical remission, disease extent, or Mayo endoscopic score.

\section{DISCUSSION}

Although the concept of "deep remission" has developed in $\mathrm{CD}$, it has not been replicated in those with UC. Most studies on mucosal healing focus on endoscopic scores, and the data from various trials suggests that patients with Mayo score 0 (complete mucosal healing) have longer-lasting remissions. However, patients with UC who are in clinical and endoscopic remission may still have histologically active
Table 4. Factors Predicting Relapse in Patients

\begin{tabular}{|c|c|c|c|}
\hline Factor & $\begin{array}{c}\text { Relapsed } \\
(n=12)\end{array}$ & $\begin{array}{l}\text { Non-relapsed } \\
\quad(n=34)\end{array}$ & $P$-value \\
\hline \multicolumn{3}{|l|}{ Age (yr) } & 0.088 \\
\hline$<30$ & 0 & 7 & \\
\hline$\geq 30$ & 12 & 27 & \\
\hline \multicolumn{3}{|l|}{ Sex } & 0.861 \\
\hline Male & 6 & 16 & \\
\hline Female & 6 & 18 & \\
\hline \multicolumn{3}{|c|}{ Duration of clinical remission } & 0.565 \\
\hline $6 \mathrm{mo}-2 \mathrm{yr}$ & 11 & 27 & \\
\hline$>2,<5 \mathrm{yr}$ & 1 & 5 & \\
\hline$\geq 5 \mathrm{yr}$ & 0 & 2 & \\
\hline \multicolumn{3}{|c|}{ Extent of disease at diagnosis } & 0.235 \\
\hline E1 & 8 & 13 & \\
\hline E2 & 2 & 11 & \\
\hline E3 & 2 & 10 & \\
\hline \multicolumn{3}{|l|}{ Mayo score } & 0.596 \\
\hline MES 0 & 6 & 20 & \\
\hline MES 1 & 6 & 14 & \\
\hline \multicolumn{4}{|l|}{ Geboes score } \\
\hline$\geq 2 A .1(n=13)$ & 12 & 1 & 0.001 \\
\hline$\geq 2$ B. $1(n=14)$ & 8 & 6 & 0.003 \\
\hline$\geq 3.1(n=11)$ & 8 & 3 & 0.001 \\
\hline$\geq 4.1(n=8)$ & 8 & 0 & 0.001 \\
\hline
\end{tabular}

disease and are at a high risk of having a relapse, ${ }^{2,4}$ thus suggesting the need for repeat biopsy and histopathology once mucosal healing has been achieved. Current practice in UC patients is focused on achieving endoscopic mucosal healing and to date there is no consensus about when to include histological remission in the definition of mucosal healing. These observations make this analysis pertinent and are the first from Asia highlighting the discrepancy between endoscopic and histological remission for clinical outcomes of UC patients.

Of the 46 patients who were in endoscopic remission in our study, $67.3 \%$ patients $(31 / 46)$ were in histological remission, but $32.6 \%$ (15/46) still had histologically active disease. When the long-term clinical outcomes were assessed after 1 year, the rate of a sustained clinical remission was significantly higher in patients who attained histological remission than among those who showed signs of active inflammation on histopathology ( $87.1 \%$ vs. $46.6 \%, P=0.006)$. A recent study 
from the United Kingdom also reported moderate concordance between endoscopic and histological remission with $24 \%$ of patients with endoscopic remission having persistent mucosal inflammation on biopsy. These findings highlight the fact that histological remission is distinct from endoscopic mucosal healing and it is a better predictor of a sustained clinical remission. Thus, histological remission may be a better endpoint for assessing long-term clinical outcomes including risk of colon cancer, as well as effectiveness of a drug in a clinical trial.

When patients with endoscopically quiescent disease are subjected to biopsy, the histopathology may show features that suggest disease activity. These include the presence of neutrophilic infiltrates in the lamina propria, epithelial cell damage (loss of cells, mucin depletion, cryptitis, crypt abscesses, and erosion), and an increase in lymphocytes and plasma cells. The presence of neutrophils is a reliable indicator of disease activity, with a good inter-observer agreement in various studies. Histology may also predict relapse or dysplasia. Histological findings predictive of ensuing clinical relapse in patients with quiescent disease are the persistence of neutrophils, basal plasmacytosis, mildly active disease, and an elevated number of eosinophils. ${ }^{2-5}$

In our study, more than $70 \%$ of patients in endoscopic remission showed mild crypt distortion and mild to moderate increases in chronic inflammatory cells in the lamina propria. The presence of eosinophils and neutrophils in the lamina propria, cryptitis, and crypt abscesses were seen only in the histologically active group. Thus, the presence of acute inflammatory infiltrates and crypt destruction were predictors of activity and relapse. These findings are consistent with other studies. ${ }^{5,6}$

In a multivariate analysis of data from 74 patients with inactive UC, relapse was also predicted by the presence of basal plasmacytosis. ${ }^{7}$ Although we observed basal plasmacytosis and basal lymphoid aggregates in biopsies of our UC patients, they failed to reach statistical significance to predict relapse. Similar observations were made by our group in a small prospective analysis previously and therefore we believe that some of these changes can be focal and serial step sectioning and better orientation of the specimen might be required. ${ }^{8}$ This problem has considerable implications for the precision of scoring. Some index items, such as basal plasmacytosis, require perpendicular sections of well-oriented samples for accurate interpretation. Section thickness may also affect the interpretation of results. Similar observations were made by Riley et al. ${ }^{5}$ who in a study of 82 patients with UC in symptomatic and sigmoidoscopic remis- sion found an acute inflammatory cell infiltrate, presence of crypt abscesses, and mucin depletion to be associated with an increased risk of relapse. Most recently, in a retrospective analysis of a cohort of 75 patients with UC, Bessissow et al. ${ }^{7}$ showed that despite normal endoscopy, histologic investigation showed inflammatory activity (Geboes score $\geq 3.1$ ) in $40 \%$ of patients, and basal plasmacytosis in $21 \%$ of patients.

Factors such as age, gender, extent of disease, and duration of clinical remission were not found to be statistically significant in predicting relapse. We attribute this to the smaller number of patients in the analysis. A limitation of our study is that we did not analyze any of the available biological parameters but during our previous analysis these were not statistically significant. ${ }^{8}$ Bessissow et al. ${ }^{7}$ showed that on univariate analysis, the only serologic marker that favored clinical remission was $\mathrm{CRP} \leq 5 \mathrm{mg} / \mathrm{L}$, but this effect did not remain significant on multivariate analysis, which was most likely related to the fact that the inflammation was only limited to the mucosa. In addition, Schoepfer et al. ${ }^{9}$ demonstrated that CRP is an inadequate biomarker of endoscopic disease activity in UC. It is also not surprising that albumin and hemoglobin were not predictive of relapse, because in patients with prolonged mucosal healing, one would expect them to be normalized. ${ }^{1}$

Though achievement of histological healing provides a more accurate picture of recovery and improves the disease outcomes, it seems to be a relatively difficult goal to achieve. In addition to this, there are certain unresolved issues. Most of the scoring systems for endoscopy and histological features are either not validated or only partially validated. ${ }^{3,410}$ There are no standard guidelines on how often one should perform colonoscopy and biopsy inpatients in clinical remission. Also, the inflammatory process in UC may be discontinuous during the natural course of the disease or after medical treatment, thus suggesting a need for several targeted biopsies, the number and method of acquisition of which is yet not clearly defined. Also, H\&E can identify neutrophils and lymphocytes accurately but cannot determine the activation status of lymphocytes, for which immunochemistry is needed.

Thus, in conclusion, histological remission and healing serves as a better marker of treatment efficacy in patients with UC and is a better predictor of sustained remission in patients than endoscopic remission. Histologic remission and healing is an area of increased research focus and has the promise of being an important marker of treatment efficacy in UC, with the potential to guide treatment decisions in the future. 
In conclusion, mucosal healing is associated with better clinical outcomes in patients with UC; however, histologic parameters may provide a more accurate picture of the recovery of the mucosa and further improve disease outcomes. This study indicates that histologic healing may be associated with better outcomes in UC thus providing a rationale for making this a treatment goal. The present analysis is small but is a progressive step towards better defining remission in UC.

\section{FINANCIAL SUPPORT}

The authors received no financial support for the research, authorship, and/or publication of this article.

\section{CONFLICT OF INTEREST}

No potential conflict of interest relevant to this article was reported.

\section{AUTHOR CONTRIBUTION}

V.N., manuscript writing and data analysis; R.K., manuscript design and data analysis; B.G., manuscript review and editing; R.M., manuscript editing and Manuscript design; V.M., manuscript editing; N.S. and A.S., supervison, manuscript editing, manuscript design.

\section{REFERENCES}

1. D’Haens G, Sandborn WJ, Feagan BG, et al. A review of activity indices and efficacy end points for clinical trials of medical therapy in adults with ulcerative colitis. Gastroenterology 2007;132:763-786.
2. Travis SP, Higgins PD, Orchard T, et al. Review article: defining remission in ulcerative colitis. Aliment Pharmacol Ther 2011;34:113-124.

3. Geboes K, Riddell R, Ost A, Jensfelt B, Persson T, Löfberg R. A reproducible grading scale for histological assessment of inflammation in ulcerative colitis. Gut 2000;47:404-409.

4. Bryant RV, Burger DC, Delo J, et al. Beyond endoscopic mucosal healing in UC: histological remission better predicts corticosteroid use and hospitalisation over 6 years of follow-up. Gut 2016;65:408-414.

5. Riley SA, Mani V, Goodman MJ, Dutt S, Herd ME. Microscopic activity in ulcerative colitis: what does it mean? Gut 1991;32:174-178.

6. Bitton A, Peppercorn MA, Antonioli DA, et al. Clinical, biological, and histologic parameters as predictors of relapse in ulcerative colitis. Gastroenterology 2001;120:13-20.

7. Bessissow T, Lemmens B, Ferrante M, et al. Prognostic value of serologic and histologic markers on clinical relapse in ulcerative colitis patients with mucosal healing. Am J Gastroenterol 2012;107:1684-1692.

8. Azad S, Sood N, Sood A. Biological and histological parameters as predictors of relapse in ulcerative colitis: a prospective study. Saudi J Gastroenterol 2011;17:194-198.

9. Schoepfer AM, Beglinger C, Straumann A, Trummler M, Renzulli P, Seibold F. Ulcerative colitis: correlation of the Rachmilewitz endoscopic activity index with fecal calprotectin, clinical activity, C-reactive protein, and blood leukocytes. Inflamm Bowel Dis 2009;15:1851-1858.

10. Geboes K, Dalle I. Influence of treatment on morphological features of mucosal inflammation. Gut 2002;50 Suppl 3:III37-III42. 